\title{
Trying to put a name tag on Subjective Wellbeing
}

\author{
Andrada Dumbraveanu ${ }^{1}$
}

\begin{abstract}
Over the last three decades there has been a growing interest in the field of subjective wellbeing (SWB). With the emergence of happiness economics researchers have exploring the possibility of using subjective wellbeing indicators for potential policy implications. However, despite the expanding literature on the subject there is no clear definition of subjective wellbeing, or indicators such as life satisfaction or happiness.
\end{abstract}

Keywords:

JEL Classification: happiness, life satisfaction, subjective wellbeing, positive affect, negative affect

131,138

${ }^{1} \mathrm{PhD}$ student at West University of Timisoara, Romania, Faculty of Economics and Business Administration. Email: dumbraveanu.andrada@gmail.com 


\section{Introduction}

The last three decades had witnessed a growing interest in the topic of subjective wellbeing (SWB), as economists have been questioning the accuracy of the wellestablished objective well-being indicators (e.g. GDP) in quantifying the wellbeing of a nation. Alternatives to such measures are proposed in the emerging field of happiness economics - an expanding area of research which brings into focus the use of subjective indicators (e.g. happiness, life satisfaction) in quantifying the wellbeing of a country. In addition, policy makers from a variety of domains became more attentive to using subjective-wellbeing as an indicator. However, the methodology for measuring subjective wellbeing is not well established. The field itself is rather fragmented, given that there are three main terms associated with subjective wellbeing: life satisfaction, happiness, and affect. Dolan et al. (2011) consider three main policy purposes which could benefit from the use of SWB:

\section{Monitoring progress \\ 2. Informing policy design \\ 3. Policy appraisal}

For monitoring, the authors recommend the frequent measuring of wellbeing in order to be able to determine its fluctuations over time. Such a process would be of interest, as it may highlight important factors that impact citizen's wellbeing. Hence, through a close monitoring of subjective indicators, policy makers gain a more holistic view of the impact of their actions upon the quality of life for a country's residents.

Subjective wellbeing indicators can be used in various domains such as policy design, sociology, and public health programs. For example, Friedli and Parsonage (2007) highlight the salience of SWB in building a case for mental health promotion. More so, the empirical work of Clark et al. (2004) and Clark (2010) makes a case for the primacy of SWB in designing unemployment programs, given the existence of a strong correlation between a decrease of wellbeing and the lack of employment prospects.

Larsen et al. (1985) argue that happiness is comprised of three, partly independent components: the frequency and degree of positive affect, the average level of satisfaction over a certain period of time, and the absence of negative emotions. However, no measure of SWB had yet established a general acceptance, in spite of the existence of a number of scales with reasonable validity.

The topic of SWB has been studied within an increasingly large number of disciplines over the course of the years, being defined in ethical, theological, political, economic, and psychological terms (Lewinsohn et al., 1991). Taking into account the extensive range of domains that this concept touches, it is not surprising that there are several names used to label it, including happiness, objective and subjective well-being, quality of life, and 
life satisfaction. Despite the fact that every one of these terms has a somewhat different meaning, each is derived from a similar point of origin.

A definition of SWB given by McGillivray and Clarke $(2006$, p. 4) states that it is a multidimensional evaluation of life which includes cognitive judgments regarding satisfaction with life, and affective assessments of a person's emotions and moods. Veenhoven (1997) defines 'happiness' as the degree to which a person evaluates the overall quality of his present life, in its entirety, positively. Hoorn (2007) defines life satisfaction as the cognitive part of SWB which relies on an information-based assessment of one's life resulting from individual judgements over how much of their life up until that moment meets their expectations and matches their envisioned 'ideal life'. An overview of the previous definitions reveals that the prominent disparity between the two components does not entail their classification as identical. While both life satisfaction and happiness are components of subjective wellbeing, happiness can be perceived as the emotional component, strongly based on a person's affect; on the other hand, life satisfaction is based on a person's judgments. However, given the extensive literature on this topic, the previous definitions are not exhaustive. Moreover, a close examination of the literature regarding this subject will highlight that they do not provide completely the same or different definition.

Economists often use the phrase 'subjective wellbeing' as a synonym for 'happiness'. However, in psychology happiness is a much narrower concept than SWB. According to Diener (2000), the idea of a good life is not only given by the fulfilment of certain criteria such as love, pleasure, or self-insight, but is also given by the impression that people think they lead good lives. Based on this definition of quality of life, each individual is granted the right to decide whether his or her life is worthwhile. Furthermore, the author suggests that this approach to SWB relies on people's assessments of their lives, which are both affective and cognitive. This point is reinforced by the Stiglitz Commission (2009), which sees individuals as the most fitting judges of their own conditions, and hence the most accurate indicators of SWB. While this view is connected to the utilitarian school of thought, it has a wider appeal, as many cultural paradigms hold that enabling people to be happy and satisfied with their life is a universal goal of human existence.

The purpose of this paper is not provide an assessment of which measure should be used, but rather to provide an overview based on the existing literature around the concepts of subjective wellbeing, happiness, life satisfaction, and affect. Moreover, the paper attempts to provide a theoretical framework for the use of various subjective wellbeing indicators.

The paper is structured as following: the second section presents a classification of subjective wellbeing components. The third section reviews the literature related to the differences and correlations between the different previously named components. Lastly, in the fourth section conclusions are drawn, and further research avenues are suggested. 


\section{Taxonomy}

Veenhoven (1991, p.19) classified wellbeing concepts in three broad categories: objective, subjective and mixed conceptions. Table 1 illustrates the key notions at both an individual and collective level. The author distinguishes three important concepts of wellbeing: objective, subjective, and mixed conceptions. While the first component focuses on personal qualities, both at an individual and collective level, the second concept is focused on an individual's self-assessment. While the concept of objective wellbeing appears to be linked to an individual's inherent qualities (e.g wisdom), cultural, and respectively traditional characteristics of a society, subjective wellbeing is perceived as an assessment at both a collective and individual level. The mixed conceptions seem to blend both individual and collective specific characteristics that can, however, be shaped over time.

Table 1: Classification of well-being concepts

\begin{tabular}{|c|c|c|c|}
\hline & $\begin{array}{l}\text { Objective } \\
\text { Wellbeing }\end{array}$ & $\begin{array}{l}\text { Subjective } \\
\text { Wellbeing }\end{array}$ & Mixed Conceptions \\
\hline $\begin{array}{l}\text { Individual } \\
\text { Wellbeing }\end{array}$ & Personal qualities & Self-appraisals & \\
\hline - aspect & $\begin{array}{l}\text { Wisdom, stability, } \\
\text { hardiness, etc. }\end{array}$ & $\begin{array}{l}\text { Job satisfaction, self- } \\
\text { esteem, control } \\
\text { belief }\end{array}$ & $\begin{array}{l}\text { Ego strength, } \\
\text { identity }\end{array}$ \\
\hline - overall & $\begin{array}{l}\text { Need gratification, } \\
\text { self-actualization, } \\
\text { effectance }\end{array}$ & $\begin{array}{l}\text { Life satisfaction, } \\
\text { contentment, } \\
\text { hedonic level }\end{array}$ & $\begin{array}{l}\text { (mental) health, } \\
\text { adjustment, } \\
\text { individual morale }\end{array}$ \\
\hline Collective & Societal qualities & $\begin{array}{l}\text { social } \\
\text { climate }\end{array}$ & \\
\hline - aspect & $\begin{array}{l}\text { coherence, justice, } \\
\text { equal chances, } \\
\text { stability, etc. }\end{array}$ & $\begin{array}{l}\text { acceptance of } \\
\text { political } \\
\text { order, mutual trust, } \\
\text { belief in national } \\
\text { progress }\end{array}$ & $\begin{array}{l}\text { social integration, } \\
\text { anomy }\end{array}$ \\
\hline - overall & viability, capacity & group morale & livability \\
\hline \multicolumn{4}{|l|}{$\begin{array}{l}\text { Mixed } \\
\text { Conceptions }\end{array}$} \\
\hline - aspects & $\begin{array}{l}\text { economic prosperity, } \\
\text { safety, freedom, } \\
\text { equality, etc }\end{array}$ & emancipation & \\
\hline - overall & welfare, progress & Alienation & $\begin{array}{l}\text { well-being } \\
\text { broadest } \\
\text { sense }\end{array}$ \\
\hline
\end{tabular}

Source: Veenhoven, 1991, "Questions on happiness: classical topics, modern answers, blind spots" (Available at: http://repub.eur.nl/pub/16149/91c-full.pdf) 
According to the Stiglitz Commission (2009) SWB comprises various aspects (cognitive evaluations of one's life, positive emotions such as joy and pride, and negative emotions such as pain and worry). Every one of these aspects should be measured separately to obtain a more comprehensive appreciation of people's lives. Diener (2000) identifies a number of components to SWB: life satisfaction (a global assessment of one's life), satisfaction with important domains (e.g. job satisfaction, health satisfaction), positive affect (experiencing a number of pleasant feelings and moods), and low levels of negative affect (experiencing less unpleasant emotions and moods).

Prieto et. al (2005) identify three main approaches to measuring subjective well-being. The first approach perceives SWB as a global evaluation of life and its facets. Within this approach, knowledge regarding SWB requires access to personal global judgments of satisfaction and quality of life. Empirical research carried out under this approach typically uses large surveys, in which respondents are asked to self-assess their general happiness or satisfaction level. The second approach views SWB as a recollection of past emotional experiences. In this case, researchers assess people's evaluations of their lives by inquiring them participants about their emotions over specific time frames. As such, researchers usually ask respondents to remember whether they felt a number of relevant feelings such as 'depressed' or 'youthful'. The last approach perceives SWB as a sum of multiple emotional reactions across time. In this case, the resulting estimate of SWB is obtained by aggregating the participants' reports and examining various temporal affective variables. Similarly, Dolan et al. (2011, p.2) distinguish between three types of SWB measures: the evaluation (global assessment), second experience (feelings over short periods of time) and 'eudemonic' (reports of purpose and meaning, and worthwhile things in life). In recommend a different measure for each policy purpose (see Table 2), the authors segregate subjective wellbeing measures based on the three previously mentioned objectives: monitoring progress, informing policy design, and policy appraisal. The first component, evaluation, can be used in all three objectives. Since it involves a cognitive assessment of life as a whole, the authors suggest that life satisfaction' should be used as a means of measurement. The second concept, more related to the emotional state of an individual is deemed to be used within the monitoring process and policy appraisal through the use of measures for affect (e.g. balance of affect). Lastly, the 'eudemonic' or in other papers 'eudaimonic' component can also be used in monitoring process and policy appraisal; however as opposed to the previous component, it is based on deeper inner reflections of an individual. 
Table 2: Subjective Wellbeing Measures

\begin{tabular}{|c|c|c|c|}
\hline & Monitoring Process & $\begin{array}{l}\text { Informing Policy } \\
\text { Design }\end{array}$ & Policy Appraisal \\
\hline $\begin{array}{l}\text { Evaluation } \\
\text { Measures }\end{array}$ & Life Satisfaction & $\begin{array}{ll}\text { - } & \text { Life Satisfaction } \\
\text { - Domain } & \\
\text { Satisfaction (such } \\
\text { as relationships, } \\
\text { health, work, } \\
\text { finances, area } \\
\text { and children) }\end{array}$ & $\begin{array}{ll}\text { - } & \text { Life Satisfaction } \\
\text { - } & \text { Domain } \\
& \text { Satisfactions } \\
\text { - } & \text { Detailed 'sub'- } \\
& \text { domains } \\
\text { - } & \text { Satisfaction with } \\
& \text { services }\end{array}$ \\
\hline $\begin{array}{l}\text { Experience } \\
\text { Measures }\end{array}$ & $\begin{array}{ll}\text { - } & \text { Happiness } \\
\text { Yesterday } \\
\text { - } \quad \text { Worried } \\
\text { Yesterday }\end{array}$ & & $\begin{array}{l}\text { - Happiness and } \\
\text { worry } \\
\text { - Affect associated } \\
\text { with particular } \\
\text { activities } \\
\text { - 'Intrusive } \\
\text { thoughts' } \\
\text { relevant to the } \\
\text { context }\end{array}$ \\
\hline $\begin{array}{l}\text { 'Eudemonic' } \\
\text { Measures }\end{array}$ & $\begin{array}{l}\text { - Worthwhile } \\
\text { things in life }\end{array}$ & & $\begin{array}{l}\text { - Worthwhile } \\
\text { things in life } \\
\text { - 'Reward' from } \\
\text { activities }\end{array}$ \\
\hline
\end{tabular}

Source: Dolan, Layard, Metcalfe, 2011, "Measuring Subjective Well-being for Public Policy" (Link available at http://eprints.lse.ac.uk/35420/1/measuring-subjective-wellbeing-for-public-policy.pdf)

According Dolan et. al (2011), SWB is measured as an evaluation when people are asked to provide global assessments of their life or domains of life, such as overall satisfaction with life in general, or more specific domains such as health, job, etc. The main reason life satisfaction has been used is because of its prevalence in international and national surveys (e.g. British House Panel Survey, German Socio-Economic Panel GSOEP, World Values Survey and Eurobarometer) is because of its comprehensibility and appeal to policymakers. A similar breakdown is offered by the OECD (2013), which names three components of subjective wellbeing - life evaluation, affect, and eudaimonia. The evaluation of SWB results from an assessment of a person on their life or some specific aspect of it. These assessments are regarded to be the product of a subjective judgement by the individual, rather than existing as emergents of the description of an emotional state. Similarly, Peterson et al. (2005) define life satisfaction as the cognitive aspect of SWB and refers to people's global assessment of the quality of their life. The process of realising such an evaluation, as described by Pavot and Diener (1993) requires individuals to build a 'standard' which they consider to be appropriate for themselves, and then compare the events and experiences of their life against that standard. Based 
on the OECD (2013) the most common used measure of life satisfaction is represented by the 'life as a whole' or a similar construction. The Stiglitz Commission (2009) states that these assessments involve a cognitive exercise by each individual together with an effort to take account of and outline the full range of elements that people value. Veenhoven (1991, p.3) gives four reasons for choosing life satisfaction as an evaluator of happiness: the concept is fairly clear, the phenomenon can be measured to a fair extent, there is empirical data on this matter which can provide answers to questions raised, and focusing the "objective" conception of happiness. The author defines life satisfaction as "the degree to which an individual judges the overall quality of his life-as-a-whole favourably" and uses the term 'happiness' as a synonym. In addition to that, Andrews and Withey (1976) make the distinction between life satisfaction and affective appraisal, arguing that the first concept is more cognitively than emotionally driven.

Various domain satisfaction questions have become prominent since the analysis of job satisfaction in the labor economics domain. Diener et al. (1999) included specific domain satisfaction within the definition of SWB. An example of such a survey is the British Household Panel Survey (BHPS) which features a list of domains satisfaction (e.g. health, job, amount of leisure time). Using data from this survey, Peasgood (2008) demonstrated that partner and social life satisfaction have the highest correlation with life satisfaction. According to Schimmack (2008), life satisfaction and domain satisfaction are considered cognitive components because they are based on assessments about one's life. Another example is the study by Van Praag et al. (2003) which estimates overall life satisfaction as a function of six separate domains while controlling for individual personality effects using a German panel data set. The authors find that financial satisfaction, health satisfaction and job satisfaction are the most important determinants for general life satisfaction, followed by satisfaction with leisure time. Similarly, we have the Personal Wellbeing Index which consists of questions covering satisfaction in eight different domains, which are summed using equal weights to calculate an overall index (OECD, 2013). Cummins et. al (2002) use Personal Wellbeing Index and National Wellbeing Index to incorporate in the Australian Unity Wellbeing Index.

Diener (2000) distinguishes between life satisfaction and happiness. The author argues that, while one is based on an overall assessment of one's life, the other is a combination of frequency and intensity of pleasant emotions. According to Diener, Sandvik and Pavot (Diener 2000), the amount of time in which people experience pleasant emotions is a better predictor than positive emotional intensity of how happy the person reports being. Hence, feeling pleasant emotions most of the time and having a lower frequency of unpleasant emotions, despite the pleasant emotions being mild, is sufficient for high reports of happiness. The authors argue that happiness researchers should firstly evaluate the relative frequency of positive versus negative emotional experience. One reason for doing this is the fact that the relative frequency of positive emotions can be more accurately and validly measured. Another reason is that frequent positive affect is both necessary and sufficient to produce the state individuals perceive as "happiness", 
whereas intense positive experience is not. Lastly, a final reason to emphasize the relative frequency of positive affect in the study of the concept of happiness is that intense positive experiences can have undesirable features. These aspects are inclined to outweigh the benefit of intense positive emotions, making it debatable whether intense experiences in the long run are more valuable to the individual than less intense ones. Lastly the authors argued that, although intense positive experiences are individually desirable at the time they are experienced, they may be less related to long-term wellbeing or happiness because of two reasons: their previously mentioned side effects and their rarity.

Argyle et al. (1989) define happiness as the average level of satisfaction over a specific period, the frequency and degree of positive affect experienes, and the relative absence of negative affect. In this light, Singh and Duggal Jha (2008) demonstrate that life satisfaction and happiness also show a significant correlation. As stated earlier, the concept of life satisfaction is encompassed within the concept of happiness.

As per the earlier classification SWB also comprises an affective component focused on evaluating a person's emotion at certain point in time. The component is broken down into positive and negative affect. They reflect the amount of pleasant and unpleasant feelings that people experience in their lives. The Stiglitz Commission define this aspect as representing people's feelings (e.g. pain, worry, pleasure, etc.). To the limit in which these feelings are reported in real time, they are less prone to biases due to memory and social pressure of what is defined as being "good". Positive and Negative Affect are two independent perceptions. Firstly, positive affect points to the extent to which an individual experiences positive emotional states (e.g. joy, interest, and confidence). The second concept - negative affect - refers to the limit to which an individual experiences negative emotions such as fear, sadness and anger (Snyder and Lopez, 2002). While positive affect is perceived as being unidimensional - positive emotions are strongly correlated with each other, and hence can be represented on a single axis of measurement - negative affect may be regarded as multi-dimensional (e.g. feeling anger without feeling any fear or sadness (OECD, 2013). Dolan et al. (2011) identify a similar dimension of SWB, under the name of "experience". This component is related to the idea of a state of wellbeing solely based on feelings pertaining to the respondent during some point in time. According to Crisp (2006), in this case pleasure and pain are the only elements that are good or bad for anyone. Consequently, this may be perceived as the amount of affect felt in any moment (including both positive and negative emotions). Hence, this perspective of well-being is regarded as the average balance of pleasure (or enjoyment) over pain, measured over the relevant period. However, studies, such as the one from Diener and Emmons (1984), indicate that negative and positive affect are to a certain extent can be separated one of another and should be measured separately. Two methods of evaluating experienced wellbeing are the Ecological Momentary Assessment (EMA) and the Day Reconstruction Method (DRM). The first method is based on reports of wellbeing at certain points in time and includes other approaches (e.g. recording of 
events) and also comprises self-reports of the respondent's own behavioirs and physiological measures (Dolan et al. 2011)

Given the multi-dimensional structure of affect, there arises the question of the relationship between affective state and life satisfaction. In their paper from 1999 Kahneman et al. (OECD 2013) hightlight the existence of a good/bad axis on which people are able to place experiences based on the emotional states there are going through. The authors argue that people are able to make an overall judgement about the impact of their affective state at a particular point in time. Kahneman's point is that affective states can be compared, and that one can therefore reasonably aggregate measures of current affect. For this reason, affect measures are sometimes reported in terms of affect balance, which captures the net balance between positive and negative affect (Kahneman and Krueger, 2006).

According to Blanchflower (2009), experience-based measures and evaluations may sometimes return similar results, but often they do not. Knabe et al. (2010) used DRM data on affect. The authors found unemployed people, that have been in this situation for over one year, and people who we employed. Additionally, through the use of the DRM framework the authors find differences in various measures of wellbeing. They found that while asking people about their life satisfaction points that unemployment makes people unhappy, the measures of instant utility over the course of the day do not find any significant differences in wellbeing between employed and unemployed people. Diener et al. (2010), use data from the Gallup Poll to assess the correlation between income and ladder of life responses, and feelings respectively. The authors discover that income is more highly correlated with ladder of life responses than with feelings, which in turn were more highly correlated with health.

Eudaimonia goes above the person's reflective assessment focusing on the person's development. These perceptions differ significantly from the evaluative and affective components, as they are concerned with capabilities as much as with final outcome and have a more instrumental focus. Despite there being a general consensus on the difference between life evaluations and affect, the conceptual structure of eudaimonic wellbeing is less pronounced. For instance, it is not clear that eudaimonic measures of wellbeing capture important aspects of people's subjective perceptions about their own wellbeing that are not covered either by life valuatations or affect. In his paper from 1989 Ryff argues that within eudemonic theories individuals are regarded as possesing basic psychological needs. Hurka in turn outlines that this will lead towards an increase in wellbeing regardless of any pleasure they may bring. According to Ryff and Keyes, individuals each report on how much meaning their lives have, usually in an evaluative sense. Hence the authors classify such responses under SWB but with quotations to highlight the blurred boundaries. (Dolan et al. 2011)

More recently, White and Dolan assessed the reward corresponding with activities using the DRM method. The authors outline a number of differences between those activities that people find 'pleasurable' as compared to 'rewarding'. For instance time 
spent with the family is considered more rewarding than watching television. (Dolan et. al 2011)

In respect to the paper's research purposes, we perceive life satisfaction as being the cognitive component of subjective wellbeing, through which an individual conducts a self-assessment of his life as a whole. Secondly, based on the definitions provided by Diener (2000) and Veenhoven (1997) we perceive happiness as an assessment of one's overall with regards to positive emotions. Hence, and individual's happiness being influenced by the frequency of positive emotions during the course of his existence. Lastly, we perceived the affect components as indicators able to capture a picture of happiness during a short time frame.

Regarding the differences between SWB and happiness, Bruni and Porta (2007) highlight that psychologists distinguish among life satisfaction which is perceived as a cognitive element, affection which is the emotional or affective element and subjective wellbeing (SWB), which is regarded as a long-run state of wellbeing, comprising both the affective and cognitive component. Additionally, the authors suggest that SWB comprises by four components pleasant emotions, unpleasant emotions, global life judgment (overall life assessment) and domain satisfaction (marriage, health, leisure etc). On the other hand, happiness is a more limited concept than SWB and distinct from life satisfaction. Although both concepts are components of SWB, life satisfaction showcases individuals' perceived distance from their aspirations while happiness results from a balance between positive and negative affect. Regarding the relationship between eudaimonic wellbeing and life satisfaction, Clark and Senik (2011) find a correlation between life satisfaction and four different aspects of eudaimonic wellbeing, spanning between 0.25 and 0.29 . Diener et al. (2009) report a correlation of $0.62(\mathrm{~N}=$ 563, $\mathrm{p}<0.001$ ) between their Psychological Well-Being Scale and the evaluative Satisfaction with Life Scale, and correlations of 0.62 and 0.51 respectively between the Psychological Well-Being Scale and the positive and negative subscales of the Scale of Positive and Negative Experience ( $\mathrm{N}=563, \mathrm{p}<0.001$ in all cases). Ryff and Keyes (1995) discovered that self-acceptance and environmental mastery were associated with evaluations but that positive relations with others, purpose in life and personal growth were less correlated.

As we can see from the above streams of literature life satisfaction (or evaluation of life) and affect are the most common components in SWB. However, as previously mentioned, life satisfaction involves a conscious evaluation of one's life while happiness is based on frequency of positive emotions. Moreover, with regards to policy design we observe that the last affective component is more volatile than the evaluative one, hence the previously mentioned one is perceived as being best suited for policy design purposes.

However, another key terms exists within the literature of SWB - happiness. The concept, while still not clearly placed in any classification, is oftentimes found in research on this topic. Generally speaking, when people are asked what do they mean when they coin the word "happiness", they offer two types of answers. Oftentimes they 
describe it as being a state of joy or a state of satisfaction. The first answer is an emotion, the second a cognition, the result of reflection. Another key aspect in the domain is the difference between life satisfaction and happiness. Typically, happiness is regarded as being an emotion or feeling state, whereas life satisfaction refers to a more cognitive, judgmental process. Easterline (2001) argues that economists have used the terms "happiness" and "life satisfaction" interchangeably as measures of subjective wellbeing. However, there is no consensus on what "happiness" means or how it is defined. Hence, instead of attempting to define happiness from an external perspective, economists are striving to achieve this through other means. Frey and Stutzer (2002) argue that there are two opposing concepts of happiness (subjective and objective happiness). The authors suggest that the to capture them is through experience sampling measures. The first notion - subjective happiness - asks individuals how happy they feel. It results from surveys where people are asked to commit a self-assessment about how happy they feel, all things considered. Today several surveys exist that evaluate happiness. One type of question asks "Taken all together, how would you say things are these days: would you say that you are very happy, pretty happy or not too happy?" (For example, the General Social Surveys). Another commonly used type of question asks people to rate their life satisfaction, on a scale from 0 to 10 (for example, the World Values Survey-WVS). The second concept - objective happiness - has the purpose of capturing happiness through the measurement of brain waves. Lastly, a third way to capture happiness is through assessing people's moods and emotions several times a day for a prolonged time.

Authors such Ferre-i-Carbonell (2002) and Veenhoven (1997) argue that SWB is commonly perceived and measured either in its life satisfaction or in its happiness conceptions. However, the life satisfaction conception is regarded as being less volatile and more cognitive oriented than happiness (Meadow et al., 1992; Sirgy et al., 1995). Authors such as Argyle (Rojas, 2004) state that satisfaction is one of the main components of happiness. Somewhat similar to other works in literature, instead of using the concept of happiness, the author argues that joy is the emotional part and satisfaction is the cognitive part - a reflective appraisal, a judgment of how well things are going, and have been going. In this case joy has been perceived as the affective component, based on the frequency of positive emotions.

\section{Measurement of Subjective Wellbeing}

According to Dolan, Layard and Metcalfe (2011), using general happiness has given similar results in terms of impact of key variables. The Gallup Poll uses Cantril's (1965) "ladder of life". This involves asking respondents to evaluate their current life on a scale from 0 (worst possible life) to 10 (best possible life). However, according to Helliwell (2008) there are some differences between life satisfaction and the ladder of life, especially in the relation with income. Furthermore, Dolan, Layard and Metcalfe also argue that evaluation can also refer to general affect. The authors present Bradburn's Affect Balance Scale (1969) and the Positive and Negative Affect Scale developed by 
Watson et. al. in 1988, which require responses to general statements about affect. However, in a study by Diener, Lucas and Scollon (2006), happiness is perceived as having several separable domains, such as life satisfaction and domain-specific satisfaction. In paper reassessing the happiness treadmill model, the authors suggest that various types of well-being may change at different rates or different directions. The authors tested on several domains of life satisfaction and found that not all individuals who increased in work satisfaction increased in marital satisfaction.

Krueger and Schkade (2007) find that life satisfaction and affect display a correlation of 0.6 when assessed two weeks apart. For measurement of life satisfaction they used a question identical to the one used in the WVS while for the affective experience the Experience Sampling Method was used. The authors discovered that both overall life satisfaction measures and affective experience measures derived from the DRM displayed test-retest correlations in the range of .50-.70. The resulting figures, while lower than the reliability ratios typically found for education, income and many other common micro economic variables, were regarded as sufficiently high to return informative estimates for much of the research that is currently being undertaken on subjective well-being, particularly in cases where group means are being compared (e.g. rich vs poor, employed vs unemployed) and the benefits of statistical aggregation apply. Life evaluation, positive and negative affect and eudaimonic well-being are all conceptually distinct. The OECD (2013) offers a model of the various elements of a measurement framework for subjective well-being (Figure 1). The model emphasises three dimensions involved in the measurement of subjective well-being. These are: the measurement concept; the sub-components of well-being; and determinants. The measurement concept encompasses three main notions: life satisfaction, affect and eudaimonic wellbeing. This concept is strongly related to the sub-components concept which highlights the main domains found in each key notion.

\section{Figure 1: Subjective Wellbeing Measurement Framework}

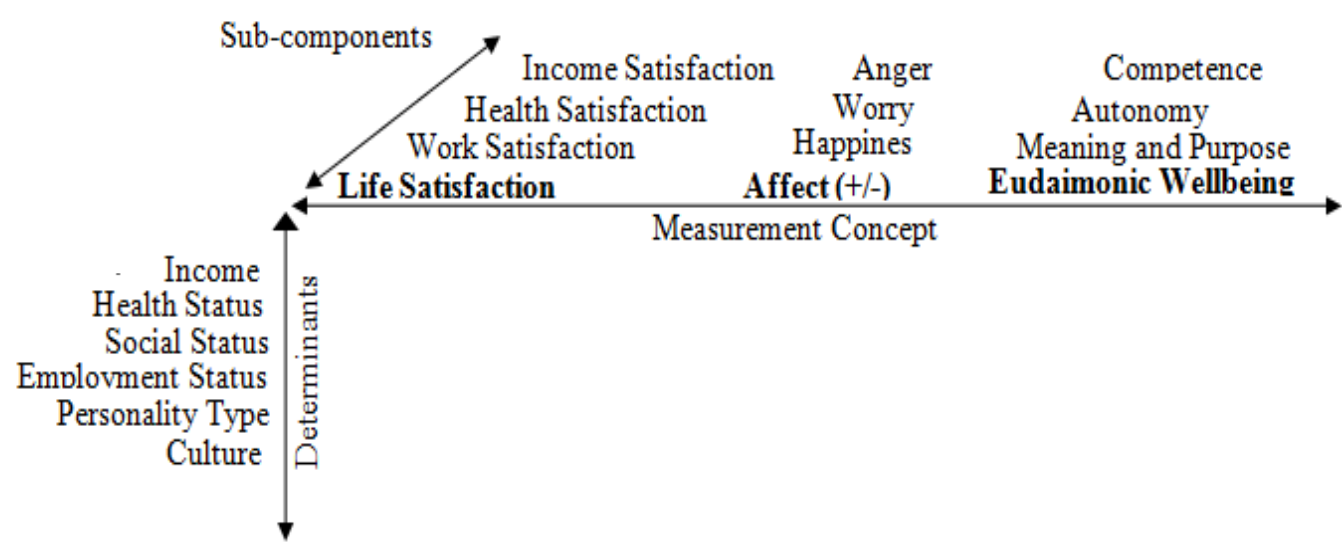

Source: OECD, 2013, “OECD Guidelines on Measuring Subjective Well-being” (Link available at:http://www.oecd.org/statistics/Guidelines\%20on\%20Measuring\%20Subjective\%20Wellbeing.pdf). 
Singh and Duggal Jha (2008) show that that there is a positive correlation between happiness and positive affect, and life satisfaction respectively. While the correlation between happiness and negative affect is negative and statistically significant. Additionally, negative affect shows significant negative correlations with Life Satisfaction $(-0.16, \mathrm{p}<0.01)$.

The ONS uses a balanced approach when measuring subjective wellbeing. The organization keeps track of the different ways that subjective wellbeing can be assessed. Questions are grouped according to type of subjective well-being measure (evaluative, experience and eudemonic) and depending on the level of detail that they provide and how they could relate to different purposes of public policy. The most general measures can be used for overall monitoring. More detailed domain and affect questions could be used for policy formulation. Finally policy appraisal is likely to use the most detailed measures which are specific to particular activities and services (Dolan et al., 2011).

\section{Public policy implications}

Wellbeing frameworks typically involve only objective indicators such as GDP, GNI or other related measures of economic activity, which undoubtedly offer important information regarding the quality of life in a country. However, there is a growing realization that subjective wellbeing indicators could provide important information to complement the view on citizen's quality of life.

Van Hoorn (2009) identifies four different policy uses for SWB: SWB as a policy, SWB as complement to existing measures of wellbeing, SWB as a measuring rod in cost-benefit analyses and the use of SWB in the construction of poverty statistics. For the first use, the author argues that SWB as policy goal involves something that is intrinsically good. According to Dolan and White (Van Hoorn, 2009) can be used in public policy design without it being a clearly outlined goal. The central argument behind this approach is based on the simple premise that higher levels of SWB are preferred over lower levels of SWB, hence giving policy makers relevant information about the impact of their policies. With this regard, governments have the possibility to evaluate their policies or base their decisions on the expected effect of their actions on SWB. Additional literature highlighting this type of policy implication include Diener (2000), and Diener and Seligman (2004). With regards to the second use, SWB can be used as a means to assess the costs and benefits of alternative actions. An example is the study from Frey et. al (2007) in which they assess the cost of terrorism for the Republic of Ireland, between 1970-1999. The paper explained the differences in life satisfaction based on reported levels or terrorism household and a number of other personal characteristics. The reference paper with regards to the last use is the one by Van Praag (Van Hoorn, 2009). The author used the subjective survey-based approach to assess what is referred to as "utility of income". The analysis has turned up two main findings. Firstly, the utility 
function differs over people. Secondly, the observed differences are connected objectively observable characteristics of respondents, such as income.

Chapple (2010) highlights the importance of subjective wellbeing for social policy. With regards to family policy, the author highlights the positive effect marriage on both men and women, as does having children with the condition of being married. Also, evidence suggests that for teenage children parental income has a positive impact on their subjective wellbeing. Regarding the impact of redistributive policies on subjective wellbeing is dependent on how a country's citizen's perceive their society, their preferences regarding this society and their beliefs on how it functions. The author highlights the concept of "limited altruism" in which others are not complete strangers but are members of the same group or the same community.

From the above mentioned stream of literature, we observe not only the broad domains in which subjective wellbeing can provide important insights, but also how these indicators are gaining increasing importance in the eyes researchers.

\section{Concluding remarks}

The purpose of the paper was to provide an overview from the literature on the concept of subjective wellbeing, together with its components life satisfaction, happiness and affect. While there seems to be a common understanding of the term of subjective wellbeing, there is still no clear definition with regards to the concept of happiness. Moreover, we aim to highlight the importance of subjective wellbeing with regards to policy design.

As the above mentioned literature highlighted, some authors perceive happiness as a synonym to subjective wellbeing, with two components happiness and life satisfaction. On the other hand, authors such as Ed Diener, regard happiness as a separate component of subjective wellbeing, related to the emotional side of an individual.

When measuring subjective wellbeing despite the notion used, whether is was happiness or life satisfaction authors used survey questions involving the respondent's assessment of his life as whole. The main rational for using this approach is that the evaluation component is based on cognitive processes which are less volatile than happiness.

With regards to policy design, although there are initiatives, such as the one driven by the ONS, to gather SWB for use in policy design, there are still challenges to implement such initiatives. (e.g. subjectivism of the participants, as well as the time it takes to gather and clean a large data set). Nonetheless, the use of such SWB indicators is likely to provide a holistic view regarding citizen's quality of life, highlighting important aspects for individuals such as health, leisure time and income.

Further research should be focused towards a more clear definition on the concept of wellbeing, and more importantly on the concept of happiness. As the literature on this topic has been increasing at a significant rate, a clear classification of these terms and 
concepts would aid future papers when establishing their goals and methodological framework.

\section{References}

Andrews, F. M., Withey, S. B., 1976. "Social indicators of wellbeing", available at: http://www.erin.utoronto.ca/ w3psyuli/SWBStructure.pdf

Argyle, M., Martin, M., Crossland, J. 1989. "Happiness as a function of personality and social encounters", Recent advances in social psychology: an international perspective, 189-203.

Blanchflower, D., 2009. "International Evidence on Well-being”, NBER Working Paper No 14318, available at: http://www.nber.org/papers/w14318

Chapple, S., 2010. "Subjective well-being and social policy", available at: http://ec.europa.eu/social/BlobServlet?docId=6704\&langId=en

Clark, A., 2010. "Work, Jobs and Well-being Across the Millennium", available at: http://ftp.iza.org/dp3940.pdf

Clark, A., Senik, C., 2011. "Is happiness different from flourishing? Cross-country evidence from the ESS", available at: http://halshs.archivesouvertes.fr/docs/00/56/18/67/PDF/wp201104.pdf

Clark, A.E., Lucas, R.E., Georgellis, Y., Diener, E., 2004. "Unemployment Alters the Set Point for Life Satisfaction", Psychological Science, vol. 15 no. 1, 8-13.

Crisp, R., (2006). "Hedonism reconsidered”, Philosophy and Phenomenological Research, 73, 619-645.

Cummins, R.A, Eckersley, R., Pallant, J., van Vugt, J., Misajon, R., 2002. "Developing a national index of subjective wellbeing: the Australian Unity Wellbeing Index", available at: http://www.uvm.edu/ pdodds/teaching/courses/2009-08UVM300/docs/others/everything/cummins2003a.pdf

Bruni, Luigino and Pier Luigi Porta. (2007). "Handbook on the Economics of Happiness", available

at: https://www.google.com/url?sa=t\&rct=j\&q=\&esrc=s\&source=web\&cd=1\&cad=r ja\&uact $=8 \&$ ved $=0 \mathrm{CBsQFjAA \& url=http} \% 3 \mathrm{~A} \% 2 \mathrm{~F} \% 2 \mathrm{Fwww}$.scribd.com $\% 2 \mathrm{Fdoc} \% 2$ F81680538\%2FHandbook-on-the-Economics-of-Happiness-Bruni-and-Porta2007\&ei=Vb0hVJeNA4XgyQPK3YGwAQ\&usg=AFQjCNFg1ITswDgKxYDgzoFvDEJ DVSfJEg\&sig2=J00v7HEkr6BLQTxsw9FzGg

Diener, E. 2000. "Subjective well-being: The science of happiness, and a proposal for national index", American Psychologist, 55, 34-43.

Diener, E., Emmons, R.A., 1984. "The independence of positive and negative affect", Journal of Personality and Social Psychology, 47: 1105-1117.

Diener, E., Kahneman, D., Arora, R., Harter, J., Tov, W., 2009. “Income's differential influence on judgements of life versus affective wellbeing", Social Indicators Research Series, Vol. 39, 851-864. 
Diener, E., Lucas, R., Scollon, C., 2006. "Beyond the Hedonic Treadmill, Revising the Adaptation Theory of Well-Being", available at: http://www.wisebrain.org/papers/BeyondHedonicTreadmill.pdf

Diener, E., Ng, W., Harter, J. Arora, R., 2010. "Wealth and Happiness Across the World: Material Prosperity Predicts Life Evaluation, Whereas Psychosocial Prosperity Predicts Positive Feeling", Journal of Personality and Social Psychology, 99, 5261.

Diener, E., Seligman, M., 2004. "Beyond Money: Toward an Economy of Well-Being", available at: http://www.iadb.org/res/files/qol/diener.pdf

Diener, E., Suh, E.M., Lucas, E.R., Smith, H., 1999."Subjective Wellbeing: Three Decades of Progress", Psychological Bulletin, 125 (2), 276-302.

Dolan, P., Layard, R., Metcalfe, R., 2011. "Measuring Subjective Wellbeing for Public Policy: Recommendations on Measures", available online at: http://cep.lse.ac.uk/pubs/download/special/cepsp23.pdf

Easterline, R.A., 2001. "Income and Happiness: Towards a Unified Theory", Economic Journal, 111(473), 465-484.

Ferrer-i-Carbonell, A., 2002. "Subjective Questions to Measure Welfare and Well-being", Tinbergen Institute Discussion Papers 02-020/3, Tinbergen Institute.

Frey, B., Stutzer, A., 2002. "The economics of happiness", available at: http://www.bsfrey.ch/articles/365_02.pdf

Friedli, L., Parsonage, M., 2007. "Mental Health Promotion: Building an Economic Case", available online

at: http://www.chex.org.uk/media/resources/mental_health/Mental\%20Health\%2 0Promotion\%20-\%20Building\%20an\%20Economic\%20Case.pdf

Helliwell, J., 2008. "Life satisfaction and quality of development", NBER Working Paper No. 14507, available at: http://www.nber.org/papers/w14507.pdf

Kahneman, D., Krueger, A.B., 2006. "Developments in the measurement of subjective well-being", Journal of Economic Perspectives, 20(1), 3-24.

Knabe, A., Ratzel, S., Schob, R., Weimann, J., 2010. "Dissatisfied with Life but having A Good Day: Time-Use and Well-Being of the Unemployed", Economic Journal, 120: 867- 889.

Krueger, A.B., Schkade, D.A., 2007. "The Reliability of Subjective Well-Being Measures", NBER Working Paper No. 13027, available at: http://www.nber.org/papers/w13027.pdf

Larsen, R.J., Diener, E., Emmons, Robert., Griffin, S., 1985. "The satisfaction with life scale", University of Illinois, available at: http://internal.psychology.illinois.edu/ ediener/Documents/Diener-EmmonsLarsen-Griffin_1985.pdf

Lewinsohn, P.M., Redner, J.E., Seeley, J.R., 1991. "The relationship between life satisfaction and psychosocial variables: new perspectives", available at: https://www.google.com/url?url=http://scholar.google.com/scholar_url\%3Fhl \%3Dro\%26q\%3Dhttp://www.researchgate.net/publication/27486202_Subjecti 
ve_well-

being__an_interdisciplinary_perspective/file/5046351b2031f81f2b.pdf\%2523pa ge\%253D149\%26sa\%3DX\%26scisig\%3DAAGBfm27cJwhRmYVnX8rFrGMKfkBo_ $\mathrm{dD} 2 \mathrm{Q} \% 260 i \% 3 D$ scholarr\&rct=j\&q=\&esrc=s\&sa=X\&ei=Z5sgVODpF4vmyQPgloL4 BA\&ved=0CBkQgAMoADAA\&usg=AFQjCNHVsyjV-ZORTWP6ZWRTU8kHq9nMGw McGillivray, M., Clarke, M., 2006. "Understanding Human Well-being”, available at: http://archive.unu.edu/unupress/sample-chapters/1130-

UnderstandingHumanWell-Being.pdf

Meadow, H. L., Mentzer, J. T., Rahtz, D. R., Sirgy, M. J., 1992. “A Life Satisfaction Measure Based on Judgment Theory", Social Indicators Research 26, pp 23-59.

OECD, 2013, "OECD Guidelines on Measuring Subjective Well-being" (Link available at:http://www.oecd.org/statistics/Guidelines\%20on\%20Measuring\%20Subjecti ve\%20Well-being.pdf

Pavot, W., Diener, E., 1993. "Review of the Satisfaction With Life Scale", available at: http://internal.psychology.illinois.edu/ ediener/Documents/Pavot-

Diener_1993.pdf

Peasgood, T., 2008. "Measuring well-being for public policy". PhD thesis, Imperial College London.

Peterson, C., Park, N., Seligman, M., 2005. "Orientations to happiness and life satisfaction: the full life versus the empty life", Journal of Happiness Studies 6:25-41, available at: http://www.itari.in/categories/higherpurpose/orientations_to_happiness.pdf

Prieto, C., Diener, E., Tamir, M., Scollon, C., Diener, M., 2005. "Integrating the diverse definitions of happiness: a time sequential framework of subjective wellbeing", available at: http://ink.library.smu.edu.sg/cgi/viewcontent.cgi?article=1921\&context=soss_re search

Rojas, M., 2004. "A Life Satisfaction Conception and a Domains-of-Life Approach", available

http://unpan1.un.org/intradoc/groups/public/documents/ICAP/UNPAN029029 .pdf

Ryff, C. D., Keyes, C. L., 1995. "The structure of psychological well-being revisited", Journal of Personality and Social Psychology 69, 719727.

Schimmack, U., 2008. The structure of subjective well-being, The science of subjective well-being, 97-123.

Singh, K, Duggal Jha, S., 2008. "Positive and Negative Affect, and Grit as predictors of Happiness and Life Satisfaction", Indian Institute of Technology, Delhi, available at: http://medind.nic.in/jak/t08/s1/jakt08s1p40.pdf

Sirgy, M. J. et. al. ,1995, “A Life Satisfaction Measure: Additional Validational Data for the Congruity Life Satisfaction Measure", Social Indicators Research 34, $237-259$.

Snyder, C. R., Lopez, S. J., 2002. "The handbook of positive psychology". New York: Oxford University Press 
Stiglitz, J.E., Sen, A., 2009. "Report by the Commission on the Measurement of Economic Performance and Social Progress", available at: http://www.stiglitz-senfitoussi.fr/documents/rapport_anglais.pdf

Van Hoorn, A., 2007. "A SHORT INTRODUCTION TO SUBJECTIVE WELL-BEING: ITS MEASUREMENT, CORRELATES AND POLICY USES", available at: http://www.oecd.org/site/worldforum06/38331839.pdf

Van Hoorn, A., 2009. "Measurement and Public Policy Uses of Subjective Well-Being", available at: http://papers.ssrn.com/sol3/papers.cfm?abstract_id=2489927

van Praag, B.M.S., Frijters, P., Ferrer-i-Carbonell, A. (2003). The anatomy of subjective well-being. Journal of Economic Behavior and Organization, 51: 29-49.

Veenhoven, R., 1991. "Questions on happiness: classical topics, modern answers, blind spots", available at: https://www.google.com/url?sa=t\&rct=j\&q=\&esrc=s\&source=web\&cd=1\&cad=r ja\&uact=8\&ved=0CB0QFjAA\&url=http $\% 3 \mathrm{~A} \% 2 \mathrm{~F} \% 2 \mathrm{Frepub}$. eur.nl $\% 2 \mathrm{Fpub} \% 2 \mathrm{~F} 16$ $149 \% 2 \mathrm{~F} 91 \mathrm{c}-$

full.pdf\&ei=Ip8gVI_UBIW_ywPrv4LoAQ\&usg=AFQjCNHolDuDwmoHIoBk05MtRB kqPUIW0g\&sig2=KsyjnS99S4wZxZbejuGccw\&bvm=bv.75775273,d.bGQ

Veenhoven, R., 1997. "ADVANCES IN UNDERSTANDING HAPPINESS”, Revue Québécoise de Psychologie, 1997, vol 18, pp 29-74. Available at: http://www2.eur.nl/fsw/research/veenhoven/Pub1990s/97c-full.pdf 